\title{
Sexta declaración de la Selva Lacandona (2005)
}

Ejército Zapatista De Liberación Nacional (EZLN)

Ésta es nuestra palabra sencilla que busca tocar el corazón de la gente humilde y simple como nosotros, pero, también como nosotros, digna y rebelde. Ésta es nuestra palabra sencilla para contar de lo que ha sido nuestro paso y en donde estamos ahora, para explicar cómo vemos el mundo y nuestro país, para decir lo que pensamos hacer y cómo pensamos hacerlo, y para invitar a otras personas a que se caminan con nosotros en algo muy grande que se llama México y algo más grande que se llama mundo. Esta es nuestra palabra sencilla para dar cuenta a todos los corazones que son honestos y nobles, de lo que queremos en México y el mundo. Ésta es nuestra palabra sencilla, porque es nuestra idea el llamar a quienes son como nosotros y unirnos a ellos, en todas partes donde viven y luchan.

\section{DE LO QUE SOMOS}

Nosotros somos los zapatistas del EZLN, aunque también nos dicen "neo zapatistas". Bueno, pues nosotros los zapatistas del EZLN nos levantamos en armas en enero de 1994 porque vimos que ya está bueno de tantas maldades que hacen los poderosos, que sólo nos humillan, nos roban, nos encarcelan y nos matan, y nada que nadie dice ni hace nada. Por eso nosotros dijimos que " $i$ Ya Basta!", o sea que ya no vamos a permitir que nos hacen menos y nos traten peor que como animales. $Y$ entonces, también dijimos que queremos la democracia, la libertad y la justicia para todos los mexicanos, aunque más bien nos concentramos en los pueblos indios. Porque resulta que nosotros del EZLN somos casi todos puros indígenas de acá de Chiapas, pero no 
queremos luchar sólo por su bien de nosotros o sólo por el bien de los indígenas de Chiapas, o sólo por los pueblos indios de México, sino que queremos luchar junto con todos los que son gente humilde y simple como nosotros y que tienen gran necesidad y que sufren la explotación y los robos de los ricos y sus malos gobiernos aquí en nuestro México y en otros países del mundo.

Y entonces nuestra pequeña historia es que nos cansamos de la explotación que nos hacían los poderosos y pues nos organizamos para defendernos y para luchar por la justicia. Al principio no somos muchos, apenas unos cuantos andamos de un lado a otro, hablando y escuchando a otras personas como nosotros. Eso hicimos muchos años y lo hicimos en secreto, o sea sin hacer bulla. O sea que juntamos nuestra fuerza en silencio. Tardamos como 10 años así, y ya luego pues nos crecimos y pues ya éramos muchos miles. Entonces nos preparamos bien con la política y las armas y de repente, cuando los ricos están echando fiesta de año nuevo, pues les caímos en sus ciudades y ahí nomás las tomamos, y les dejamos dicho a todos que aquí estamos, que nos tienen que tomar en cuenta. $Y$ entonces pues que los ricos se dieron su buena espantada y nos mandaron a sus grandes ejércitos para acabarnos, como de por sí hacen siempre que los explotados se rebelan, que los mandan acabar a todos. Pero nada que nos acabaron, porque nosotros nos preparamos muy bien antes de la guerra y nos hicimos fuertes en nuestras montañas. $Y$ ahí andaban los ejércitos buscándonos y echándonos sus bombas y balas, y ya estaban haciendo sus planes de que de una vez matan a todos los indígenas porque bien no saben quién es zapatista y quién no es. Y nosotros corriendo y combatiendo, combatiendo y corriendo, como de por sí hicieron nuestros antepasados. Sin entregarnos, sin rendimos, sin derrotarnos.

$Y$ entonces que la gente de las ciudades se sale a las calles y empieza con su gritadera de que se pare la guerra. $Y$ entonces pues nos paramos nuestra guerra y lo escuchamos a esos hermanos y hermanas de la ciudad, que nos dicen que tratemos de llegar a un arreglo, o sea un acuerdo con los malos gobiernos para que se soluciona el problema sin matazón. Y pues nosotros lo hicimos caso a la gente, porque 
esa gente es como decimos "el pueblo", o sea el pueblo mexicano. Así que hicimos a un lado el fuego y sacamos la palabra.

$Y$ resulta que los gobiernos dijeron que sí se van a estar bien portados y van a dialogar y van a hacer acuerdos y los van a cumplir. $Y$ nosotros dijimos que está bueno, pero también pensamos que está bueno que conocemos a esa gente que se salió a las calles para parar la guerra. Entonces, mientras estamos dialogando con los malos gobiernos, pues también lo hablamos a esas personas y vimos que la mayoría era gente humilde y sencilla como nosotros, y ambos entendemos bien por qué luchamos, o sea ellos y nosotros. $Y$ a esa gente la llamamos "sociedad civil" porque la mayoría no era de los partidos políticos, sino que era gente así común y corriente, como nosotros, gente sencilla y humilde.

Pero resulta que los malos gobiernos no querían un buen arreglo, sino que nomás era su maña de que vamos a hablar y hacer acuerdo, y estaban preparando sus ataques para eliminarnos de una vez. Y entonces pues varias veces nos atacaron, pero no nos vencieron porque nos resistimos bien y mucha gente en todo el mundo se movilizó. Y entonces los malos gobiernos se pensaron que el problema es que mucha gente está viendo lo que pasa con el EZLN, y empezó su plan de hacer como si no pasa nada. Y mientras, pues bien que nos rodea, o sea que nos pone un cerco, y espera que, como de por sí nuestras montañas están retiradas, pues la gente se olvide porque está lejos la tierra zapatista. Y cada tanto los malos gobiernos prueban y nos tratan de engañar o nos atacan, como en febrero de 1995 que nos aventó una gran cantidad de ejércitos pero no nos derrotó. Porque, como luego dicen, no estábamos solos y mucha gente nos apoyó y nos resistimos bien.

$Y$ pues ya los malos gobiernos tuvieron que hacer acuerdos con el EZLN y esos acuerdos se llaman "Acuerdos de San Andrés" porque "San Andrés" se llama el municipio donde se firmaron esos acuerdos. Y en esos diálogos no estábamos solitos nosotros hablando con los del mal gobierno, sino que invitamos a mucha gente y organizaciones que estaban o están en la lucha por los pueblos indios de México, y todos decían su palabra y todos sacábamos acuerdo de cómo vamos a decir con los malos gobiernos. Y así fue ese diálogo, que no sólo 
estaban los zapatistas por un lado y los gobiernos por el otro, sino que con los zapatistas estaban los pueblos indios de México y los que los apoyan. $Y$ entonces en esos acuerdos los malos gobiernos dijeron que sí van a reconocer los derechos de los pueblos indios de México y van a respetar su cultura, y todo lo van a hacer ley en la Constitución. Pero, ya luego que firmaron, los malos gobiernos se hicieron como que se les olvida y pasan muchos años y nada que se cumplen esos acuerdos. Al contrario, el gobierno atacó a los indígenas para hacerlos que se echan para atrás en la lucha, como el 22 de diciembre de 1997, fecha en la que el Zedillo mandó matar a 45 hombres, mujeres, ancianos y niños en el poblado de Chiapas que se llama ACTEAL. Este gran crimen no se olvida tan fácil y es una muestra de cómo los malos gobiernos no se tientan el corazón para atacar y asesinar a los que se rebelan contra las injusticias. Y mientras pasa todo eso, pues los zapatistas estamos dale y dale que se cumplan los acuerdos, y resistiendo en las montañas del sureste mexicano.

Y entonces empezamos a hablarnos con otros pueblos indios de México y sus organizaciones que tienen y lo hicimos un acuerdo con ellos que vamos a luchar juntos por lo mismo, o sea por el reconocimiento de los derechos y la cultura indígenas. $Y$ bueno, pues también nos apoyó mucha gente de todo el mundo y personas que son muy respetadas y que su palabra es muy grande porque son grandes intelectuales, artistas y científicos de México y de todo el mundo. Y también hicimos encuentros internacionales, o sea que nos juntamos a platicar con personas de América y de Asia y de Europa y de África y de Oceanía, y conocimos sus luchas y sus modos, y dijimos que son encuentros "intergalácticos" nomás por hacernos los chistositos y porque invitamos también a los de otros planetas pero parece que no llegaron, o tal vez sí llegaron pero no lo dijeron claro.

Pero como quiera los malos gobiernos no cumplían, y entonces pues hicimos un plan de hablar con muchos mexicanos para que nos apoyan. Y entonces pues primero hicimos, en 1997, una marcha a la Ciudad de México que se llamó "de los 1,111" porque iban un compañero o compañera por cada pueblo zapatista, pero el gobierno no hizo caso. Y luego, en 1999, hicimos una consulta en todo el país y ahí se miró que la 
mayoría sí está de acuerdo con las demandas de los pueblos indios, pero los malos gobiernos tampoco hicieron caso. $Y$ ya por último, en 2001, hicimos la que se llamó la "marcha por la dignidad indígena" que tuvo mucho apoyo de millones de mexicanos y de otros países, y llegó hasta donde están los diputados y senadores, o sea el Congreso de la Unión, para exigir el reconocimiento de los indígenas mexicanos.

Pero resulta que no, que los políticos que son del partido PRI, el partido PAN y el partido PRD se pusieron de acuerdo entre ellos y nomás no reconocieron los derechos y la cultura indígenas. Eso fue en abril del 2001 y ahí los políticos demostraron claro que no tienen nada de decencia y son unos sinvergüenzas que sólo piensan en ganar sus buenos dineros como malos gobernantes que son. Esto hay que recordarlo porque ya van a ver ustedes que ahora van a decir que sí van a reconocer los derechos indígenas, pero es una mentira que echan para que votemos por ellos, pero ya tuvieron su oportunidad y no cumplieron.

Y entonces pues ahí lo vimos claro que de balde fueron el diálogo y la negociación con los malos gobiernos de México. O sea que no tiene caso que estamos hablando con los políticos porque ni su corazón ni su palabra están derechos, sino que están chuecos y echan mentiras de que sí cumplen, pero no. O sea que ese día que los políticos del PRI, PAN y PRD aprobaron una ley que no sirve, pues lo mataron de una vez al diálogo y claro dijeron que no importa lo que acuerdan y firman porque no tienen palabra. $Y$ pues ya no hicimos ningún contacto con los poderes federales, porque entendimos que el diálogo y la negociación se habían fracasado por causa de esos partidos políticos. Vimos que no les importaron la sangre, la muerte, el sufrimiento, las movilizaciones, las consultas, los esfuerzos, los pronunciamientos nacionales e internacionales, los encuentros, los acuerdos, las firmas, los compromisos. Así que la clase política no sólo cerró, una vez más, la puerta a los pueblos indios; también le dio un golpe mortal a la solución pacífica, dialogada y negociada de la guerra. Y también ya no se puede creer que cumpla los acuerdos a los que llegue con cualquiera. Ahí lo vean para que saquen experiencia de lo que nos pasó.

$Y$ entonces pues nosotros lo vimos todo eso y nos pensamos en nuestros corazones que qué vamos a hacer. 
Y lo primero que vimos es que nuestro corazón ya no es igual que antes, cuando empezamos nuestra lucha, sino que es más grande porque ya tocamos el corazón de mucha gente buena. $Y$ también vimos que nuestro corazón está como más lastimado, que sea más herido. Y no es que está herido por el engaño que nos hicieron los malos gobiernos, sino porque cuando tocamos los corazones de otros pues tocamos también sus dolores. O sea que como que nos vimos en un espejo.

\section{DE DONDE ESTAMOS AHORA}

Entonces, como zapatistas que somos, pensamos que no bastaba con dejar de dialogar con el gobierno, sino que era necesario seguir adelante en la lucha a pesar de esos parásitos haraganes de los políticos. El EZLN decidió entonces el cumplimiento, solo y por su lado (o sea que se dice "unilateral" porque sólo un lado), de los Acuerdos de San Andrés en lo de los derechos y la cultura indígenas. Durante 4 años, desde mediando el 2001 hasta mediando el 2005, nos hemos dedicado a esto, y a otras cosas que ya les vamos a decir.

Bueno, pues empezamos entonces a echarle ganas a los municipios autónomos rebeldes zapatistas, que es como se organizaron los pueblos para gobernar y gobernarse, para hacerlos más fuertes. Este modo de gobierno autónomo no es inventado así nomás por el EZLN, sino que viene de varios siglos de resistencia indígena y de la propia experiencia zapatista, y es como el autogobierno de las comunidades. O sea que no es que viene alguien de afuera a gobernar, sino que los mismos pueblos deciden, de entre ellos, quién y cómo gobierna, y si no obedece pues lo quitan. O sea que si el que manda no obedece al pueblo, lo corretean, se sale de autoridad y entra otro.

Pero entonces vimos que los municipios autónomos no estaban parejos, sino que había unos que estaban más avanzados y tenían más apoyos de la sociedad civil, y otros estaban más abandonados. O sea que faltaba organizar para que fuera más parejo. $Y$ también vimos que el EZLN con su parte político-militar se estaba metiendo en las decisiones que le tocaban a las autoridades democráticas, como quien dice "civiles". Y aquí el problema es que la parte político-militar del EZLN no 
es democrática, porque es un ejército, y vimos que no está bien eso de que está arriba lo militar y abajo lo democrático, porque no debe de ser que lo que es democrático se decida militarmente, sino que debe ser al revés: o sea que arriba lo político democrático mandando y abajo lo militar obedeciendo. $\mathrm{O}$ tal vez es mejor que nada abajo sino que puro planito todo, sin militar, y por eso los zapatistas son soldados para que no haya soldados. Bueno, pero entonces, de este problema, lo que hicimos fue empezar a separar lo que es político-militar de lo que son las formas de organización autónomas y democráticas de las comunidades zapatistas. Y así, acciones y decisiones que antes hacía y tomaba el EZLN, pues se fueron pasando poco a poco a las autoridades elegidas democráticamente en los pueblos. Claro que se dice fácil, pero en la práctica cuesta mucho, porque son muchos años, primero de la preparación de la guerra y ya luego mero de la guerra, y se va haciendo costumbre de lo político-militar. Pero como quiera lo hicimos porque es nuestro modo que lo que decimos pues lo hacemos, porque si no, pues entonces para qué vamos a andar diciendo si luego no hacemos.

Así fue como se nacieron las Juntas de Buen Gobierno, en agosto de 2003, y con ellas se continuó con el autoaprendizaje y ejercicio del "mandar obedeciendo".

Desde entonces y hasta la mitad de 2005, la dirección del EZLN ya no se metió a dar órdenes en los asuntos civiles, pero acompañó y apoyó a las autoridades elegidas democráticamente por los pueblos, y, además, vigiló que se informara bien a los pueblos y a la sociedad civil nacional e internacional de los apoyos recibidos y en qué se utilizaron. $Y$ ahora estamos pasando el trabajo de vigilancia del buen gobierno a las bases de apoyo zapatistas, con cargos temporales que se rotan, de modo que todos y todas aprendan y realicen esa labor. Porque nosotros pensamos que un pueblo que no vigila a sus gobernantes, está condenado a ser esclavo, y nosotros peleamos por ser libres, no por cambiar de amo cada seis años.

El EZLN, durante estos 4 años, también le pasó a las Juntas de Buen Gobierno y a los Municipios Autónomos, los apoyos y contactos que, en todo México y el mundo, se lograron en estos años de guerra y resistencia. Además, en ese tiempo, el EZLN fue construyendo un 
apoyo económico y político que les permita a las comunidades zapatistas avanzar con menos dificultades en la construcción de su autonomía y en mejorar sus condiciones de vida. No es mucho, pero es muy superior a lo que se tenía antes del inicio del alzamiento, en enero de 1994. Si usted mira uno de esos estudios que hacen los gobiernos, va a ver que las únicas comunidades indígenas que mejoraron sus condiciones de vida, o sea su salud, educación, alimentación, vivienda, fueron las que están en territorio zapatista, que es como le decimos nosotros a donde están nuestros pueblos. $Y$ todo eso ha sido posible por el avance de los pueblos zapatistas y el apoyo muy grande que se ha recibido de personas buenas y nobles, que les decimos "sociedades civiles", y de sus organizaciones de todo el mundo. Como si todas esas personas hubieran hecho realidad eso de que "otro mundo es posible", pero en los hechos, no en la pura habladera.

Y entonces los pueblos han tenido buenos avances. Ahora hay más compañeros y compañeras que están aprendiendo a ser gobierno. Y, aunque poco a poco, ya más mujeres se están entrando en estos trabajos, pero todavía sigue faltando respeto a las compañeras y que ellas participen más en los trabajos de la lucha. Y luego, también con las Juntas de Buen Gobierno, ha mejorado la coordinación entre los municipios autónomos y la solución de problemas con otras organizaciones y con las autoridades oficialistas. Y también se mejoró mucho en los proyectos en las comunidades, y es más parejo el reparto de proyectos y apoyos que da la sociedad civil de todo el mundo: se ha mejorado la salud y la educación aunque todavía falta un buen tanto para ser lo que debe de ser, igual con la vivienda y la alimentación, y en algunas zonas se ha mejorado mucho el problema de la tierra porque se repartieron las tierras recuperadas a los finqueros, pero hay zonas que siguen sufriendo por falta de tierras para cultivar. Y luego pues se mejoró mucho el apoyo de la sociedad civil nacional e internacional, porque antes cada quien iba para donde más le latía, y ahora las Juntas de Buen Gobierno las orientan a donde es más necesario. Y, por lo mismo, en todas partes hay más compañeros y compañeras que están aprendiendo a relacionarse con las personas de otras partes de México y del mundo, están aprendiendo a respetar y a exigir respeto, están 
aprendiendo que hay muchos mundos y que todos tienen su lugar, su tiempo y su modo, y así hay que respetarse mutuamente entre todos.

Bueno, pues nosotros los zapatistas del EZLN nos dedicamos ese tiempo a nuestra fuerza principal, o sea a los pueblos que nos apoyan. Y pues algo sí se ha mejorado la situación, o sea que no hay quien diga que de balde fue la organización y la lucha zapatistas, sino que, aunque nos acaben completamente, nuestra lucha sí sirvió de algo.

Pero no sólo se crecieron los pueblos zapatistas, sino que también se creció el EZLN. Porque lo que pasó en este tiempo es que nuevas generaciones renovaron toda nuestra organización. O sea que como que le metieron nueva fuerza. Los comandantes y comandantas, quienes estaban en su madurez en el inicio del alzamiento en 1994, tienen ahora la sabiduría de lo aprendido en la guerra y en el diálogo de 12 años con miles de hombres y mujeres de todo el mundo. Los miembros del CCRI, la dirección político- organizativa zapatista, ahora aconsejan y orientan a los nuevos que van entrando en nuestra lucha, y a los que van ocupando cargos de dirección. Ya tiene tiempo que los "comités" (que es como les decimos nosotros) han estado preparando toda una nueva generación de comandantes y comandantas que, después de un período de instrucción y prueba, empiezan a conocer los trabajos de mando organizativo y a desempeñarlos. $Y$ pasa también que nuestros insurgentes, insurgentas, milicianos, milicianas, responsables locales y regionales, así como las bases de apoyo, que eran jóvenes en el inicio del alzamiento, son ya hombres y mujeres maduros, veteranos combatientes y líderes naturales en sus unidades y comunidades. $Y$ quienes eran niños en aquel enero de 94, son ya jóvenes que han crecido en la resistencia, y han sido formados en la digna rebeldía levantada por sus mayores en estos 12 años de guerra. Estos jóvenes tienen una formación política, técnica y cultural que no teníamos quienes iniciamos el movimiento zapatista. Esta juventud alimenta ahora, cada vez más, tanto nuestras tropas como los puestos de dirección en la organización. $Y$, bueno, todos nosotros hemos visto los engaños de la clase política mexicana y la destrucción que sus acciones provocan en nuestra patria. $Y$ hemos visto las grandes injusticias y matazones que hace la globalización neoliberal en todo el mundo. Pero de eso les decimos más luego. 
Así el EZLN ha resistido 12 años de guerra, de ataques militares, políticos, ideológicos y económicos, de cerco, de hostigamiento, de persecución, y no nos han vencido, no nos hemos vendido ni rendido, y hemos avanzado. Más compañeros de muchas partes se han entrado en la lucha, así que, en lugar de que nos hacemos más débiles después de tantos años, nos hacemos más fuertes. Claro que hay problemas que se pueden resolver separando más lo político-militar de lo civil-democrático. Pero hay cosas, las más importantes, como son nuestras demandas por las que luchamos, que no se han logrado cabalmente.

Según nuestro pensamiento y lo que vemos en nuestro corazón, hemos llegado a un punto en que no podemos ir más allá y, además, es posible que perdamos todo lo que tenemos, si nos quedamos como estamos y no hacemos nada más para avanzar. O sea que llegó la hora de arriesgarse otra vez y dar un paso peligroso pero que vale la pena. Porque tal vez unidos con otros sectores sociales que tienen las mismas carencias que nosotros, será posible conseguir lo que necesitamos y merecemos. Un nuevo paso adelante en la lucha indígena sólo es posible si el indígena se junta con obreros, campesinos, estudiantes, maestros, empleados... o sea los trabajadores de la ciudad y el campo.

\section{DE CÓMO VEMOS EL MUNDO}

Ahora vamos a explicarles cómo es que vemos nosotros los zapatistas lo que pasa en el mundo. Pues vemos que el capitalismo es el que está más fuerte ahorita. El capitalismo es un sistema social, o sea una forma como en una sociedad están organizadas las cosas y las personas, y quien tiene y quien no tiene, y quien manda y quien obedece. En el capitalismo hay unos que tienen dinero o sea capital y fábricas y tiendas y campos y muchas cosas, y hay otros que no tienen nada sino que sólo tienen su fuerza y su conocimiento para trabajar; y en el capitalismo mandan los que tienen el dinero y las cosas, y obedecen los que nomás tienen su capacidad de trabajo.

Y entonces el capitalismo quiere decir que hay unos pocos que tienen grandes riquezas, pero no es que se sacaron un premio, o que se encontraron un tesoro, o que heredaron de un pariente, sino que esas 
riquezas las obtienen de explotar el trabajo de muchos. O sea que el capitalismo se basa en la explotación de los trabajadores, que quiere decir que como que exprimen a los trabajadores y les sacan todo lo que pueden de ganancias. Esto se hace con injusticias porque al trabajador no le pagan cabal lo que es su trabajo, sino que apenas le dan un salario para que coma un poco y se descanse un tantito, y al otro día vuelta a trabajar en el explotadero, que sea en el campo o en la ciudad.

Y también el capitalismo hace su riqueza con despojo, o sea con robo, porque les quita a otros lo que ambiciona, por ejemplo tierras y riquezas naturales. $\mathrm{O}$ sea que el capitalismo es un sistema donde los robadores están libres y son admirados y puestos como ejemplo.

Y, además de explotar y despojar, el capitalismo reprime porque encarcela y mata a los que se rebelan contra la injusticia.

Al capitalismo lo que más le interesa son las mercancías, porque cuando se compran y se venden dan ganancias. Y entonces el capitalismo todo lo convierte en mercancías, hace mercancías a las personas, a la naturaleza, a la cultura, a la historia, a la conciencia. Según el capitalismo, todo se tiene que poder comprar y vender. $Y$ todo lo esconde detrás de las mercancías para que no vemos la explotación que hace. $Y$ entonces las mercancías se compran y se venden en un mercado. $Y$ resulta que el mercado, además de servir para comprar y vender, también sirve para esconder la explotación de los trabajadores. Por ejemplo, en el mercado vemos el café ya empaquetado, en su bolsita o frasco muy bonitillo, pero no vemos al campesino que sufrió para cosechar el café, y no vemos al coyote que le pagó muy barato su trabajo, y no vemos a los trabajadores en la gran empresa dale y dale para empaquetar el café. $O$ vemos un aparato para escuchar música como cumbias, rancheras o corridos o según cada quien, y lo vemos que está muy bueno porque tiene buen sonido, pero no vemos a la obrera de la maquiladora que batalló muchas horas para pegar los cables y las partes del aparato, y apenas le pagaron una miseria de dinero, y ella vive retirado del trabajo y gasta un buen en el pasaje, y además corre peligro que la secuestran, la violan y la matan como pasa en Ciudad Juárez, en México. 
O sea que en el mercado vemos mercancías, pero no vemos la explotación con las que se hicieron. $Y$ entonces el capitalismo necesita muchos mercados... o un mercado muy grande, un mercado mundial.

$Y$ entonces resulta que el capitalismo de ahora no es igual que antes, que están los ricos contentos explotando a los trabajadores en sus países, sino que ahora está en un paso que se llama Globalización Neoliberal. Esta globalización quiere decir que ya no sólo en un país dominan a los trabajadores o en varios, sino que los capitalistas tratan de dominar todo en todo el mundo. $Y$ entonces al mundo, o sea al planeta Tierra, también se le dice que es el "globo terráqueo" y por eso se dice "globalización" o sea todo el mundo.

Y el neoliberalismo pues es la idea de que el capitalismo está libre para dominar todo el mundo y ni modos, pues hay que resignarse y conformarse y no hacer bulla, o sea no rebelarse. O sea que el neoliberalismo es como la teoría, el plan pues, de la globalización capitalista. Y el neoliberalismo tiene sus planes económicos, políticos, militares y culturales. En todos esos planes de lo que se trata es de dominar a todos, y el que no obedece pues lo reprimen o lo apartan para que no pasa sus ideas de rebelión a otros.

Entonces, en la globalización neoliberal, los grandes capitalistas que viven en los países que son poderosos, como Estados Unidos, quieren que todo el mundo se hace como una gran empresa donde se producen mercancías y como un gran mercado. Un mercado mundial, un mercado para comprar y vender todo lo del mundo y para esconder toda la explotación de todo el mundo. Entonces los capitalistas globalizados se meten a todos lados, o sea a todos los países, para hacer sus grandes negocios o sea sus grandes explotaciones. $Y$ entonces no respetan nada y se meten como quiera. O sea que como que hacen una conquista de otros países. Por eso los zapatistas decimos que la globalización neoliberal es una guerra de conquista de todo el mundo, una guerra mundial, una guerra que hace el capitalismo para dominar mundialmente. Y entonces esa conquista a veces es con ejércitos que invaden un país y a la fuerza lo conquistan. Pero a veces es con la economía,o sea que los grandes capitalistas meten su dinero en otro país o le prestan dinero, pero con la condición de que obedezca lo que ellos dicen. $Y$ también se 
meten con sus ideas, o sea con la cultura capitalista que es la cultura de la mercancía, de la ganancia, del mercado.

Entonces el que hace la conquista, el capitalismo, hace como quiere, o sea que destruye y cambia lo que no le gusta y elimina lo que le estorba. Por ejemplo le estorban los que no producen ni compran ni venden las mercancías de la modernidad, o los que se rebelan a ese orden. Y a esos que no le sirven, pues los desprecia. Por eso los indígenas estorban a la globalización neoliberal y por eso los desprecian y los quieren eliminar. Y el capitalismo neoliberal también quita las leyes que no lo dejan hacer muchas explotaciones y tener muchas ganancias. Por ejemplo imponen que todo se pueda comprar y vender, y como el capitalismo tiene el dinero, pues lo compra todo. Entonces como que el capitalismo destruye a los países que conquista con la globalización neoliberal, pero también como que quiere volver a acomodar todo o hacerlo de nuevo pero a su modo, o sea de modo que lo beneficie y sin lo que le estorba. Entonces la globalización neoliberal, o sea la capitalista, destruye lo que hay en esos países, destruye su cultura, su idioma, su sistema económico, su sistema político, y también destruye los modos en que se relacionan los que viven en ese país. O sea que queda destruido todo lo que hace que un país sea un país.

Entonces la globalización neoliberal quiere destruir a las Naciones del mundo y que sólo queda una sola Nación o país, o sea el país del dinero, del capital. Y el capitalismo quiere entonces que todo sea como él quiere, o sea según su modo, y lo que es diferente pues no le gusta, y lo persigue, y lo ataca, o lo aparta en un rincón y hace como que no existe.

Entonces, como quien dice que resumiendo, el capitalismo de la globalización neoliberal se basa en la explotación, el despojo, el desprecio y la represión a los que no se dejan. O sea igual que antes, pero ahora globalizado, mundial.

Pero no es tan fácil para la globalización neoliberal, porque los explotados de cada país pues no se conforman y no dicen que ya ni modo, sino que se rebelan; y los que sobran y estorban pues se resisten y no se dejan ser eliminados. $Y$ entonces por eso vemos que en todo el mundo los que están jodidos se hacen resistencias para no 
dejarse, o sea que se rebelan, y no sólo en un país sino que donde quiera abundan, o sea que, así como hay una globalización neoliberal, hay una globalización de la rebeldía.

Y en esta globalización de la rebeldía no sólo aparecen los trabajadores del campo y dé la ciudad, sino que también aparecen otros y otras que mucho los persiguen y desprecian por lo mismo de que no se dejan dominar, como son las mujeres, los jóvenes, los indígenas, los homosexuales, lesbianas, transexuales, los migrantes, y muchos otros grupos que de por sí hay en todo el mundo pero que no vemos hasta que gritan que ya basta de que los desprecien, y se levantan, y pues ya los vemos, y los oímos, y los aprendemos.

Y entonces nosotros vemos que todos esos grupos de gente están luchando contra el neoliberalismo, o sea contra el plan de la globalización capitalista, y están luchando por la humanidad.

$Y$ todo esto que vemos nos produce gran asombro por ver la estupidez de los neoliberalistas que quieren destruir toda la humanidad con sus guerras y explotaciones, pero también nos produce gran contento ver que donde quiera salen resistencias y rebeldías, así como la nuestra que es un poco pequeña pero aquí estamos. $Y$ vemos todo esto en todo mundo y ya nuestro corazón aprende que no estamos solos.

\section{DE CÓMO VEMOS A NUESTRO PAÍS QUE ES MÉXICO}

Ahora les platicamos cómo vemos lo que está pasando en nuestro México. Bueno, pues lo que vemos es que nuestro país está gobernado por los neoliberalistas. O sea que, como ya explicamos, los gobernantes que tenemos están destruyendo lo que es nuestra Nación, nuestra Patria mexicana. Y su trabajo de estos malos gobernantes no es mirar por el bienestar del pueblo, sino que sólo están pendientes del bienestar de los capitalistas. Por ejemplo, hacen leyes como las del Tratado de Libre Comercio, que pasan a dejar en la miseria a muchos mexicanos, tanto campesinos y pequeños productores, porque son "comidos" por las grandes empresas agroindustriales; tanto como 
los obreros y pequeños empresarios porque no pueden competir con las grandes trasnacionales que se meten sin que nadie les diga nada y hasta les dan gracias, y ponen sus bajos salarios y sus altos precios. $\mathrm{O}$ sea que, como quien dice, algunas de las bases económicas de nuestro México, que eran el campo y la industria y el comercio nacionales, están bien destruidas y apenas quedan unos pocos escombros que seguro también van a vender.

Y éstas son grandes desgracias para nuestra Patria. Porque pues en el campo ya no se producen los alimentos, sino sólo lo que venden los grandes capitalistas, y las buenas tierras son robadas con mañas y con el apoyo de los políticos. O sea que en el campo está pasando igual que cuando el Porfirismo, nomás que, en lugar de hacendados, ahora son unas empresas extranjeras las que tienen al campesino bien jodido. $Y$ donde antes había créditos y precios de protección, ahora sólo hay limosnas, ..y a veces ni eso.

En su lado del trabajador de la ciudad pues las fábricas cierran y se quedan sin trabajo, o se abren las que se llaman maquiladoras, que son del extranjero y que pagan una miseria por muchas horas de trabajo. $Y$ entonces no importa el precio de los productos que necesita el pueblo porque, aunque está caro o barato, pues no hay la paga. $Y$ si alguien se trabajaba en una pequeña o mediana empresa, pues ya no, porque se cerró y la compró una gran trasnacional. Y si alguien tenía un pequeño negocio, pues también se desapareció o se puso a trabajar clandestinamente para las grandes empresas que los explotan una barbaridad, y hasta ponen a trabajar a los niños y niñas. Y si el trabajador estaba en un su sindicato para demandar sus derechos legalmente, pues no, que ahora el mismo sindicato le dice que hay que apechugar que bajan el salario o la jornada de trabajo o quitan prestaciones, porque si no pues la empresa cierra y se va para otro país. $Y$ luego pues está eso del "microchangarro", que es como el programa económico del gobierno para que todos los trabajadores de la ciudad se pongan a vender chicles o tarjetas de teléfono en las esquinas. $O$ sea que pura destrucción económica también en las ciudades.

Y entonces lo que pasa es que, como la economía del pueblo está bien jodida tanto en el campo como en la ciudad, pues muchos mexicanos y 
mexicanas tienen que dejar su Patria, o sea la tierra mexicana, e irse a buscar trabajo en otro país que es Estados Unidos y ahí no los tratan bien, sino que los explotan, los persiguen y los desprecian y hasta los matan.

Entonces en el neoliberalismo que nos imponen los malos gobiernos pues no ha mejorado la economía, al contrario, el campo está muy necesitado y en las ciudades no hay trabajo. Y lo que está pasando es que México se está convirtiendo nomás en donde nacen y un rato, y otro rato se mueren, los que trabajan para la riqueza de los extranjeros principalmente de los gringos ricos. Por eso decimos que México está dominado por Estados Unidos.

Bueno, pero no sólo pasa esto, sino que también el neoliberalismo cambió a la clase política de México, o sea a los políticos, porque los hizo como que son empleados de una tienda, que tienen que hacer todo lo posible por vender todo y bien barato. Ya ven que cambiaron las leyes para quitar el artículo 27 de la Constitución y se pudieran vender las tierras ejidales y comunales. Eso fue el Salinas de Gortari, y él y sus bandas dijeron que es por bien del campo y del campesino, y que así va a prosperar y a vivir mejor. ¿Acaso ha sido así? El campo mexicano está peor que nunca y los campesinos más jodidos que cuando Porfirio Díaz. Y también dijeron que van a privatizar, o sea a vender a los extranjeros, las empresas que tenía el Estado para apoyar el bienestar del pueblo. Que porque no funcionan bien y les falta modernizarse, y que mejor venderlas. Pero, en lugar de mejorar, los derechos sociales que se conquistaron en la revolución de 1910 son ahora como para dar lástima... y coraje. $\mathrm{Y}$ también dijeron que hay que abrir las fronteras para que entre todo el capital extranjero, que así se van a apurar los empresarios mexicanos y a hacer mejor las cosas. Pero ahora vemos que ya ni hay empresas nacionales, todo se lo comieron los extranjeros, y lo que venden está peor que lo que se hacía en México.

$Y$ bueno, pues ahora también los políticos mexicanos lo quieren vender PEMEX o sea el petróleo que es de los mexicanos, y la única diferencia es que unos dicen que se vende todo y otros dicen que sólo se vende una parte. $Y$ también quieren privatizar el seguro social, y la electricidad, y el agua, y los bosques, y todo, hasta que no quede nada de México y nuestro país sólo sea como un terreno baldío o un 
lugar para su diversión de los ricos de todo el mundo, y los mexicanos y mexicanas estemos como sus sirvientes, pendientes de qué se les ofrece, mal viviendo, sin raíces, sin cultura, sin Patria pues.

O sea que los neoliberalistas lo quieren matar a México, a nuestra patria mexicana. Y los partidos políticos electorales no nada más no defienden, sino que primero que nadie son los que se ponen al servicio de los extranjeros, principalmente de los de Estados Unidos, y son los que se encargan de engañarnos, haciéndonos que miramos para otro lado mientras venden todo y se quedan ellos con la paga. Todos los partidos políticos electorales que hay ahorita, no nomás unos. Piensen ustedes si algo han hecho bien y verán que no, que puras robaderas y transas. $Y$ vean como los políticos electorales siempre tienen sus buenas casas y sus buenos carros y sus lujos. $Y$ todavía quieren que les damos las gracias y que otra vuelta votamos por ellos. $Y$ es que de plano, como luego dicen, no tienen madre. $Y$ no la tienen porque de por sí no tienen Patria, sólo tienen cuentas bancarias.

Y también vemos que crece mucho el narcotráfico y los crímenes. Y a veces pensamos que los criminales son como los presentan en los corridos o las películas, y tal vez algunos son así, pero no son los meros jefes. Los meros jefes andan bien vestidos, tienen estudios en el extranjero, son elegantes, no se andan escondiendo sino que comen en buenos restaurantes y salen en los periódicos muy bonitos y bien vestidos en sus fiestas, o sea que, como luego se dice, son "gente bien", y algunos hasta son gobernantes, diputados, senadores, secretarios de estado, empresarios prósperos, jefes de policía, generales.

¿Estamos diciendo que la política no sirve? No, lo que queremos decir es que ESA política no sirve. $Y$ no sirve porque no toma en cuenta al pueblo, no lo escucha, no le hace caso, nomás se le acerca cuando hay elecciones, y ya ni siquiera quieren votos, ya basta con las encuestas para decir quien gana. $Y$ entonces pues puras promesas de que van a hacer esto y van a hacer lo otro, y ya luego, pues anda-vete y no los vuelves a ver, mas que cuando sale en las noticias que ya se robaron mucho dinero y no les van a hacer nada porque la ley, que esos mismos políticos hicieron, los protege. 
Porque ése es otro problema, y es que la Constitución ya está toda manoseada y cambiada. Ya no es la que tenía los derechos y las libertades del pueblo trabajador, sino que ahora están los derechos y las libertades de los neoliberalistas para tener sus grandes ganancias. Y los jueces están para servir a esos neoliberalistas, porque siempre dan su palabra a favor de ellos, y a los que no son ricos pues les tocan las injusticias, las cárceles, los cementerios.

Bueno, pues aún con todo este desbarajuste que están haciendo los neoliberalistas, hay mexicanos y mexicanas que se organizan y hacen lucha de resistencia.

Y así nos enteramos que hay indígenas, que sus tierras están retiradas de aquí de Chiapas, y que hacen su autonomía y defienden su cultura y cuidan la tierra, los bosques, el agua.

$Y$ hay trabajadores del campo, o sea campesinos, que se organizan y hacen sus marchas y movilizaciones para exigir créditos y apoyos al campo.

$Y$ hay trabajadores de la ciudad que no se dejan que les quiten sus derechos o que privaticen sus trabajos, sino que protestan y se manifiestan para que no les quiten lo poco que tienen y para que no le quiten al país lo que es suyo de por sí, como la electricidad, el petróleo, la seguridad social, la educación.

$Y$ hay estudiantes que no dejan que se privatice la educación y luchan porque sea gratuita y popular y científica, o sea que no cobren, que toda la gente pueda aprender, y que en las escuelas no enseñen tarugadas.

$Y$ hay mujeres que no dejan que las traten como adorno o que las humillen y desprecien nomás por mujeres, sino que se organizan y luchan por el respeto que merecen como mujeres que son.

$Y$ hay jóvenes que no aceptan que los embrutecen con las drogas 0 que los persiguen por sus modos de ser, sino que se hacen conscientes con su música y su cultura, su rebeldía pues.

$Y$ hay homosexuales, lesbianas, transexuales y muchos modos, que no se conforman con que los burlan, y los desprecian, y los maltratan, 
y hasta los matan porque tienen otro modo que es diferente, y los tratan de anormales o delincuentes, sino que hacen sus organizaciones para defender su derecho a la diferencia.

$Y$ hay sacerdotes y monjas y los que se llaman seglares, que no están con los ricos ni resignados en la rezadera, sino que se organizan para acompañar las luchas del pueblo.

$Y$ hay los que se llaman luchadores sociales, que son hombres y mujeres que toda su vida se la han pasado luchando por el pueblo explotado, y son los mismos que participaron en las grandes huelgas y acciones obreras, en las grandes movilizaciones ciudadanas, en los grandes movimientos campesinos, y que sufrieron las grandes represiones, y como quiera, aunque algunos ya tienen edad, siguen sin rendirse, y ahí andan de un lado a otro buscando la lucha, buscando la organización, buscando la justicia, y se hacen organizaciones de izquierda, organizaciones no gubernamentales, organizaciones de derechos humanos, organizaciones de defensa de presos políticos y de aparición de los desaparecidos, publicaciones de izquierda, organizaciones de maestros o estudiantes, o sea lucha social, y hasta organizaciones político-militares, y nomás no se están quietos y mucho saben porque mucho han visto y oído y vivido y luchado.

Y así en general, nosotros vemos que en nuestro país, que se llama México, hay mucha gente que no se deja, que no se rinde, que no se vende. O sea que es digna. $Y$ eso nos da mucho contento y alegría porque con toda esa gente pues no tan fácil van a ganar los neoliberalistas y tal vez si se logra salvar a nuestra Patria de los grandes robos y destrucción que le hacen. Y pensamos que ojalá nuestro "nosotros" incluyera todas esas rebeldías...

\section{DE LO QUE QUEREMOS HACER}

Bueno, pues ahora les vamos a decir lo que queremos hacer en el mundo y en México, porque no podemos ver todo lo que pasa en nuestro planeta y quedarnos nomás callados, como si sólo nosotros estamos donde estamos. 
Pues en el mundo lo que queremos es decirle a todos los que resisten y luchan con sus modos y en sus países, que no están solos, que nosotros los zapatistas, aunque somos muy pequeños, los apoyamos y vamos a ver el modo de ayudarlos en sus luchas y de hablar con ustedes para aprender, porque de por sí lo que hemos aprendido es a aprender.

$Y$ queremos decirle a los pueblos latinoamericanos que es para nosotros un orgullo ser una parte de ustedes, aunque sea pequeña. Que bien que nos acordamos cuando hace años también se iluminaba el continente y una luz se llamaba Che Guevara, como antes se llamó Bolívar, porque a veces los pueblos agarran un nombre para decir que agarran una bandera.

Y queremos decirle al pueblo de Cuba, que ya lleva muchos años resistiendo en su camino, que no está solo y que no estamos de acuerdo con el bloqueo que les hacen y que vamos a ver el modo de mandarles algo, aunque sea maíz, para su resistencia. Y queremos decirle al pueblo norteamericano, que nosotros no revolvemos y sabemos que una cosa son los malos gobiernos que tienen y que pasan a perjudicar a todo el mundo, y otra muy diferente los norteamericanos que luchan en su país y se solidarizan con las luchas de otros pueblos. $Y$ queremos decirle a los hermanos y hermanas Mapuche, en Chile, que vemos y aprendemos de sus luchas. $Y$ a los venezolanos que bien que miramos cómo defienden su soberanía o sea el derecho de su Nación a decidir para dónde va. Y a los hermanos y hermanas indígenas del Ecuador y Bolivia les decimos que nos están dando una buena lección de historia a toda Latinoamérica porque ahora sí que le están poniendo un alto a la globalización neoliberal. Y a los piqueteros y a los jóvenes de Argentina les queremos decir eso, que los queremos. $Y$ a los que en Uruguay se quieren un mejor país que los admiramos. $Y$ a los que están sin tierra en Brasil que los respetamos. $Y$ a todos los jóvenes de Latinoamérica que está bueno lo que están haciendo y que nos da una gran esperanza.

Y queremos decirles a los hermanos y hermanas de la Europa Social, o sea la que es digna y rebelde, que no están solos. Que nos alegran mucho sus grandes movimientos contra las guerras neoliberalistas. Que miramos con atención sus formas de organización y sus modos de luchar para que tal vez algo aprendemos. Que estamos 
viendo el modo de apoyarlos en sus luchas y que no les vamos a mandar euros porque luego se devalúan por lo del relajo de la Unión Europea, pero tal vez les vamos a mandar artesanías y café para que lo comercializan y algo se ayudan en sus trabajos para la lucha. $Y$ tal vez también les mandamos pozol que da mucha fuerza en la resistencia, pero quien sabe si les mandamos porque el pozol es más bien de nuestro modo y qué tal que les perjudica la panza y se debilitan sus luchas y los derrotan los neoliberalistas.

Y queremos decirles a los hermanos y hermanas de África, Asia y Oceanía que sabemos que también se están luchando y que queremos conocer más de sus ideas y sus prácticas.

$Y$ queremos decirle al mundo que lo queremos hacer grande, tan grande que quepan todos los mundos que resisten porque los quieren destruir los neoliberalistas y porque no se dejan así nomás sino que luchan por la humanidad.

Bueno, pues en México lo que queremos hacer es un acuerdo con personas y organizaciones mero de izquierda, porque pensamos que es en la izquierda política donde mero está la idea de resistirse contra la globalización neoliberal, y de hacer un país donde haya, para todos, justicia, democracia y libertad. No como ahorita que sólo hay justicia para los ricos, sólo hay libertad para sus grandes negocios y sólo hay democracia para pintar las bardas con propaganda electoral. Y porque nosotros pensamos que sólo de la izquierda puede salir un plan de lucha para que nuestra Patria, que es México, no se muere.

Y entonces, lo que pensamos es que, con estas personas y organizaciones de izquierda, hacemos un plan para ir a todas las partes de México donde hay gente humilde y sencilla como nosotros.

$Y$ no es que vamos a decirles qué deben hacer o sea a darles orden.

Tampoco es que vamos a pedirles que voten por un candidato, que ya sabemos que los que hay son neoliberalistas.

Tampoco es que les vamos a decir que hagan igual a nosotros, ni que se levanten en armas. 
Lo que vamos a hacer es preguntarles cómo es su vida, su lucha, su pensamiento de cómo está nuestro país y de cómo hacemos para que no nos derroten.

Lo que vamos a hacer es tomar su pensamiento de la gente sencilla y humilde y tal vez encontramos en ella el mismo amor que sentimos nosotros por nuestra patria.

$Y$ tal vez encontramos un acuerdo entre los que somos sencillos y humildes $y$, juntos, nos organizamos en todo el país y ponemos de acuerdo nuestras luchas que ahorita están solas, apartadas unas de otras, y encontramos algo así como un programa que tenga lo que queremos todos, y un plan de cómo vamos a conseguir que ese programa, que se llama "programa nacional de lucha", se cumpla.

Y entonces, según el acuerdo de la mayoría de esa gente que vamos a escuchar, pues hacemos una lucha con todos, con indígenas, obreros, campesinos, estudiantes, maestros, empleados, mujeres, niños, ancianos, hombres, y con todo aquel que tenga bueno su corazón y tenga la gana de luchar para que no se acabe de destruir y vender nuestra patria que se llama "México" y que viene quedando entre el río Bravo y el río Suchiate, y de un lado tiene el océano pacífico y del otro el océano atlántico.

\section{DE COMO LO VAMOS A HACER}

Y entonces ésta es nuestra palabra sencilla que va dirigida a la gente humilde y simple de México y el mundo, y a ésta nuestra palabra de ahora la llamamos:

\section{SEXTA DECLARACIÓN DE LA SELVA LACANDONA.}

Y aquí estamos para decir, con nuestra palabra sencilla, que...

El EZLN mantiene su compromiso de cese al fuego ofensivo y no hará ataque alguno contra fuerzas gubernamentales ni movimientos militares ofensivos. 
El EZLN mantiene todavía su compromiso de insistir en la vía de la lucha política con esta iniciativa pacífica que ahora hacemos. Por lo tanto, el EZLN seguirá en su pensamiento de no hacer ningún tipo de relación secreta con organizaciones político-militares nacionales o de otros países.

EI EZLN refrenda su compromiso de defender, apoyar y obedecer a las comunidades indígenas zapatistas que lo forman y son su mando supremo, $y$, sin interferir en sus procesos democráticos internos y en la medida de sus posibilidades, contribuir al fortalecimiento de su autonomía, buen gobierno y mejora de sus condiciones de vida. O sea que lo que vamos a hacer en México y el mundo, lo vamos a hacer sin armas, con un movimiento civil y pacífico, y sin descuidar ni dejar de apoyar a nuestras comunidades.

Por lo tanto...

\section{EN EL MUNDO...}

1. Haremos más relaciones de respeto y apoyos mutuos con personas y organizaciones que resisten y luchan contra el neoliberalismo y la humanidad.

2. En la medida de nuestras posibilidades mandaremos apoyos materiales como alimentos artesanías para los hermanos y hermanas que luchan en todo el mundo.

Para empezar, vamos a pedir prestado a la Junta de Buen Gobierno de La Realidad, el Camión que se llama "Chompiras" y le caben parece que 8 toneladas, y lo vamos a llenar de maíz y tal vez dos tambos de 200 litros cada uno con gasolina o petróleo, según qué les conviene, y los vamos a entregar en la embajada de Cuba en México para que lo mandan en su pueblo cubano como un apoyo de los zapatistas para su resistencia contra el bloqueo norteamericano. O tal vez hay un lugar más acá para entregar porque siempre está retirado hasta la Ciudad de México y qué tal que se descompone el "Chompiras" y vamos a quedar mal. $Y$ eso pues hasta que sale la cosecha que ahorita está verdeando en la milpa y si no nos atacan, porque si mandamos 
en estos meses que vienen pues puro elote mandamos y no llega bien ni en tamales, mejor en noviembre o diciembre, según.

Y también vamos a hacer acuerdo con las cooperativas de mujeres de las artesanías para mandar un buen tanto de bordados a las Europas que tal vez ya no son Unión, y también tal vez mandamos café orgánico de las cooperativas zapatistas, para que lo vendan y saquen un poco de paga para su lucha. $Y$ si no se vende pues siempre pueden echar un cafecito y platicar de la lucha antineoliberal, y si hace un poco de frío pues se tapan con los bordados zapatistas que sí resisten bien hasta los lavados a mano y piedra y, además, no despintan.

Y a los hermanos y hermanas indígenas de Bolivia y Ecuador también les vamos a mandar un poco de maíz no-transgénico y nomás que no sabemos donde mero entregar para que llegue cabal pero sí estamos dispuestos para dar esta pequeña ayuda.

3. $Y$ a todos y todas que resisten en todo el mundo les decimos que hay que hacer otros encuentros intercontinentales, aunque sea otro uno. Tal vez diciembre de este año o enero próximo, hay que pensar. No queremos decir mero cuándo, porque se trata de que hacemos acuerdo parejo en todo, de dónde, de cuando, de cómo, de quién. Pero que no sea de templete donde unos pocos hablan y todos los demás escuchan, sino que sin templete, puro plano y todos hablan, pero en orden porque si no pues pura bulla y no se entiende la palabra, y con buena organización todos escuchan, y así apuntan en sus cuadernos las palabras de resistencia de otros para que luego cada quien lo platica a sus compañeros y compañeras en sus mundos. $Y$ nosotros pensamos que sea en un lugar que tenga una cárcel muy grande, porque qué tal que nos reprimen y nos encarcelan, y para no estar todos amontonados sino que presos pero, eso sí, bien organizados, y ahí en la cárcel le seguimos el encuentro intercontinental por la humanidad y contra el neoliberalismo. Entonces ahí luego les decimos cómo hacemos para ponernos de acuerdo en cómo nos vamos a poner de acuerdo. Bueno pues así es como pensamos hacer lo que queremos hacer en el mundo. Ahora sigue... 


\section{EN MÉXICO...}

1. Vamos a seguir luchando por los pueblos indios de México, pero ya no sólo por ellos ni sólo con ellos, sino que por todos los explotados y desposeídos de México, con todos ellos y en todo el país. Y cuando decimos que todos los explotados de México también estamos hablando de los hermanos y hermanas que se han tenido que ir a Estados Unidos a buscar trabajo para poder sobrevivir.

2. Vamos a ir a escuchar y hablar directamente, sin intermediarios ni mediaciones, con la gente sencilla y humilde del pueblo mexicano $y$, según lo que vamos escuchando y aprendiendo, vamos a ir construyendo, junto con esa gente que es como nosotros, humilde y sencilla, un programa nacional de lucha, pero un programa que sea claramente de izquierda o sea anticapitalista o sea antineoliberal, o sea por la justicia, la democracia y la libertad para el pueblo mexicano.

3. Vamos a tratar de construir o reconstruir otra forma de hacer política, una que otra vuelta tenga el espíritu de servir a los demás, sin intereses materiales, con sacrificio, con dedicación, con honestidad, que cumpla la palabra, que la única paga sea la satisfacción del deber cumplido, o sea como antes hacían los militantes de izquierda que no paraban ni con golpes, cárcel o muerte, mucho menos con billetes de dólar.

4. También vamos a ir viendo de levantar; una lucha para demandar que hacemos una nueva Constitución o sea nuevas leyes que tomen en cuenta las demandas del pueblo mexicano como son: techo, tierra, trabajo, alimento, salud, educación, información, cultura, independencia, democracia, justicia, libertad y paz. Una nueva Constitución que reconozca los derechos y libertades del pueblo, y defienda al débil frente al poderoso.

\section{PARA ESTO....}

El EZLN enviará una delegación de su dirección para hacer este trabajo en todo el territorio nacional y por tiempo indefinido. Esta delegación zapatista, junto con las organizaciones y personas de izquierda 
que se sumen a esta Sexta Declaración de la Selva Lacandona, irá a los lugares a donde nos inviten expresamente.

También avisamos que el EZLN establecerá una política de alianzas con organizaciones y movimientos no electorales que se definan, en teoría y práctica, como de izquierda, de acuerdo a las siguientes condiciones:

No a hacer acuerdos arriba para imponer abajo, sino a hacer acuerdos para ir juntos a escuchar y a organizar la indignación; no a levantar movimientos que sean después negociados a espaldas de quienes los hacen, sino a tomar en cuenta siempre la opinión de quienes participan; no a buscar regalitos, posiciones, ventajas, puestos públicos, del Poder o de quien aspira a él, sino a ir más lejos de los calendarios electorales; no a tratar de resolver desde arriba los problemas de nuestra Nación, sino a construir DESDE ABAJO Y POR ABAJO una alternativa a la destrucción neoliberal, una alternativa de izquierda para México.

Sí al respeto recíproco a la autonomía e independencia de organizaciones, a sus formas de lucha, a su modo de organizarse, a sus procesos internos de toma de decisiones, a sus representaciones legítimas, a sus aspiraciones y demandas; y sí a un compromiso claro de defensa conjunta y coordinada de la soberanía nacional, con la oposición intransigente a los intentos de privatización de la energía eléctrica, el petróleo, el agua y los recursos naturales.

O sea que, como quien dice, invitamos a las organizaciones políticas y sociales de izquierda que no tengan registro, y a las personas que se reivindiquen de izquierda que no pertenezcan a los partidos políticos con registro, a reunimos en tiempo, lugar y modo que les propondremos en su oportunidad, para organizar una campaña nacional, visitando todos los rincones posibles de nuestra patria, para escuchar y organizar la palabra de nuestro pueblo. Entonces es como una campaña, pero muy otra porque no es electoral.

Hermanos y hermanas:

Ésta es nuestra palabra que declaramos:

En el mundo vamos a hermanarnos más con las luchas de resistencia contra el neoliberalismo y por la humanidad. 
Y vamos a apoyar, aunque sea un poco, a esas luchas.

$Y$ vamos, con respeto mutuo, a intercambiar experiencias, historias, ideas, sueños.

En México, vamos a caminar por todo el país, por las ruinas que ha dejado la guerra neoliberal y por las resistencias que, atrincheradas, en él florecen.

Vamos a buscar, y a encontrar, a alguien que quiera a estos suelos y a estos cielos siquiera tanto como nosotros.

Vamos a buscar, desde La Realidad hasta Tijuana, a quien quiera organizarse, luchar, construir acaso la última esperanza de que esta Nación, que lleva andando al menos desde el tiempo en que un águila se posó sobre un nopal para devorar una serpiente, no muera.

Vamos por democracia, libertad y justicia para quienes nos son negadas.

Vamos con otra política, por un programa de izquierda y por una nueva constitución.

Invitamos a los indígenas, obreros, campesinos, maestros, estudiantes, amas de casa, colonos, pequeños propietarios, pequeños comerciantes, micro empresarios, jubilados, discapacitados, religiosos y religiosas, científicos, artistas, intelectuales, jóvenes, mujeres, ancianos, homosexuales y lesbianas, niños y niñas, para que, de manera individual o colectiva participen directamente con los zapatistas en esta CAMPAÑA NACIONAL para la construcción de otra forma de hacer política, de un programa de lucha nacional y de izquierda, y por una nueva Constitución.

Y pues ésta es nuestra palabra de lo que vamos a hacer y de cómo lo vamos a hacer. Ahí lo vean si es que le quieren entrar.

$Y$ les decimos a los hombres y mujeres que tengan bueno su pensamiento en su corazón, que estén de acuerdo con esta palabra que sacamos y que no tengan miedo, o que tengan miedo pero que lo controlen, pues que digan públicamente si están de acuerdo con esta idea que estamos declarando y pues así vamos viendo de una vez quién y cómo y en dónde y cuándo es que se hace este nuevo paso en la lucha. 
Por mientras lo piensan, les decimos que, hoy, en el sexto mes del año de 2005, los hombres, mujeres, niños y ancianos del Ejército Zapatista de Liberación Nacional ya nos decidimos y ya suscribimos esta Sexta Declaración de la Selva Lacandona, y firmaron los que saben y los que no lo pusieron su huella, pero ya son menos los que no saben porque ya se avanzó la educación aquí en este territorio en rebeldía por la humanidad y contra el neoliberalismo, o sea en cielo y tierra zapatistas.

Y ésta fue nuestra sencilla palabra dirigida a los corazones nobles de la gente simple y humilde que resiste y se rebela contra las injusticias en todo el mundo.

\section{¡DEMOCRACIA!}

\section{¡LIBERTAD!}

\section{¡JUSTICIA!}

Desde las montañas del Sureste Mexicano.

Comité Clandestino Revolucionario Indígena Comandancia General del Ejército Zapatista de Liberación Nacional. México, en el mes sexto, o sea en junio, del año del 2005. 